\title{
Predictive factors of neurological complications and one-month mortality after liver transplantation
}

\author{
Katherine A. Fu ${ }^{1}$, Joseph DiNorcia ${ }^{1,3}$, Linda Sher ${ }^{1,3}$, Shamsha A. Velani ${ }^{1,2}$, Shahrzad Akhtar ${ }^{1}$, \\ Laura A. Kalayjian ${ }^{1,2}$ and Nerses Sanossian ${ }^{1,2 *}$ \\ 1 Keck School of Medicine, University of Southern California, Los Angeles, CA, USA \\ 2 Department of Neurology, University of Southern California, Los Angeles, CA, USA \\ ${ }^{3}$ Department of Hepatobiliary, Pancreas and Abdominal Organ Transplant Surgery, University of Southern California, Los Angeles, CA, USA
}

Edited by:

Edward Manno, Cleveland Clinic, USA

Reviewed by:

Joshua P. Klein, Brigham and

Women's Hospital, USA

Joseph D. Burns, Boston University, USA

*Correspondence:

Nerses Sanossian, Roxanna Todd Hodges Comprehensive Stroke Clinic, University of Southern California, 1520 San Pablo Street, STE 3000, Los

Angeles, CA 90033, USA

e-mail:nsanossi@usc.edu
Background: Neurological complications are common after orthotopic liver transplantation (OLT). We aimed to characterize the risk factors associated with neurological complications and mortality among patients who underwent OLT in the post-model for end-stage liver disease (MELD) era.

Methods: In a retrospective review, we evaluated 227 consecutive patients at the Keck Hospital of the University of Southern California before and after OLT to define the type and frequency of and risk factors for neurological complications and mortality.

Results: Neurological complications were common $(n=98)$, with encephalopathy being most frequent $(56.8 \%)$, followed by tremor $(26.5 \%)$, hallucinations $(11.2 \%)$, and seizure (8.2\%). Factors associated with neurological complications after OLT included preoperative dialysis, hepatorenal syndrome, renal insufficiency, intra-operative dialysis, preoperative encephalopathy, preoperative mechanical ventilation, and infection. Preoperative infection was an independent predictor of neurological complications (OR 2.83, 1.47-5.44). Onemonth mortality was $8.8 \%$ and was independently associated with urgent re-transplant, preoperative intubation, and intra-operative arrhythmia.

Conclusion: Neurological complications are common in patients undergoing OLT in the post-MELD era, with encephalopathy being most frequent. An improved understanding of the risk factors related to both neurological complications and one-month mortality posttransplantation can better guide perioperative care and help improve outcomes among OLT patients.

Keywords: liver transplant, neurological complications, mortality

\section{INTRODUCTION}

Orthotopic liver transplantation (OLT) is the only definitive treatment for end-stage liver disease and is being performed with increasing frequency in the United States (1). Post-operative complications after OLT are a significant source of morbidity and mortality $(2,3)$, with neurological complications such as encephalopathy, akinetic mutism, seizures, and stroke reportedly occurring in $8 \%$ to as high as $75 \%$ of cases, often within 30 days of transplantation (4-7). Neurological complications occur more commonly after OLT than after other solid organ transplantations such as heart and kidney (8), and studies have suggested that these higher rates are related to preoperative hepatic encephalopathy, the unfavorable clinical condition of patients awaiting transplantation (e.g., malnutrition, renal insufficiency, hyponatremia, coagulopathy), and the complexity of the operation (9). Postoperatively, patients with neurological complications may become less compliant with immunosuppressive medications, increasing the risk of rejection and graft loss $(10,11)$. Research has demonstrated that patients with neurological complications after OLT have longer hospitalizations and increased rates of infection, re-transplantation, and mortality $(12,13)$.
Defining the risk factors for neurological complications and one-month mortality after OLT can help identify high-risk patients and guide perioperative care with the intention to minimize neurological complications, morbidity, and mortality. Identifying primary risk factors is particularly relevant given the high acuity recipients in the post-model for end-stage liver disease (MELD) era, as the MELD system prioritizes the allocation of organs to patients with the most severe liver disease (14). Studies have suggested that neurological complications can be attributed to factors such as cerebral infarction, a poorly functioning allograft, intracranial hemorrhage, infection, or immunosuppressant toxicity (15).

While complications after OLT have been described previously (15), risk factors for post-operative neurological complications and one-month mortality are not well-characterized. In this study, we defined the type and frequency of neurological complications in patients who underwent OLT in the postMELD era. We identified hypothesis-generating pre-operative and intra-operative risk factors for neurological complications and one-month mortality to help improve future patient outcomes after OLT. 


\section{MATERIALS AND METHODS \\ DATASET AND STUDY POPULATION}

We reviewed the hospital records of 227 consecutive cases of adults who underwent OLT between July 18, 2003 and August 19, 2006 at the Keck Hospital of the University of Southern California. A standardized form was used to collect demographic, historical, surgical, laboratory and radiological data. Data was collected for the period beginning one week prior to transplant and extending to one month post-transplant. The Institutional Review Board approved the study.

Transplants were characterized as partial living donor or cadaveric and as first transplant, urgent re-transplant (performed $\leq$ one month from initial transplant), non-urgent re-transplant (performed $>$ one month from initial transplant), transfusion free, and simultaneous liver-kidney transplant. MELD scores were calculated on the day of transplant and included exception points where applicable in cases of hepatocellular carcinoma. Operating room records were reviewed for intra-operative events, surgery duration, pressors used, and hypotension (defined as systolic blood pressure $<90 \mathrm{mmHg}$ ). For re-transplants, preoperative data, labs, and intra-operative records from the first transplant were recorded. Neurological complications were identified by chart review by the study's investigators, including resident physicians and attending physicians in the Department of Neurology. These complications were then confirmed by the study's multiple board certified neurologist investigators. These complications were defined as new neurological problems or a worsening of known neurological disorders in one month after OLT. Neurological complications were further characterized by pre-specified type and date of onset relative to OLT.

\section{STATISTICAL ANALYSIS}

An analysis was done to determine whether neurological complications post-OLT were associated with one-month mortality post-OLT. Univariate analyses of mortality and neurological complications after OLT were performed using Fisher's Exact Test and Wilcoxon Two Sample Test where appropriate, using a $p$-value $<0.05$ threshold for significance. Using a $p<0.2$ threshold for significance, multivariate logistic regression analysis was performed controlling for potential risk factors for neurologic complications after OLT; these included medical co-morbidities such as dialysis and renal insufficiency, preoperative conditions such as encephalopathy and infection, and intra-operative events such as dialysis. Six cases were excluded from this analysis due to intraoperative deaths. A similar multivariate regression analysis was performed controlling for potential risk factors for one-month mortality following OLT, such as race, transplant type, medical comorbidities, preoperative conditions and intra-operative events, again using a $p<0.2$ threshold.

\section{RESULTS}

We identified 228 consecutive adult patients who underwent OLT. One patient record could not be found, thus 227 patients were included in the study. Demographic factors are listed in Table 1. The population was $37 \%$ female with a mean age of 52 years and mostly Hispanic (48.9\%) or Caucasian (30.4\%). The mean MELD score was 22 (range from 2 to 40 ). The most common liver diseases were hepatocellular carcinoma (20.7\%), hepatitis C (19.8\%), and alcohol-induced cirrhosis (15.9\%). The majority of transplants were cadaveric $(79.7 \%)$ and first-time transplants $(94.3 \%)$.

\section{NEUROLOGICAL COMPLICATIONS}

The one-month incidence of neurological complications was $44.3 \%$ (98/221). Sixty-six patients had one neurological complication, 27 had two complications, and five had three complications. The most common complication was encephalopathy $(53.06 \%)$, followed by tremor $(27.55 \%)$ and seizure $(8.16 \%)$. Neurological complications among patients during the first postoperative month following OLT are summarized in Table 2. Neurological complications were not associated with one-month mortality.

Univariate analysis of risk factors for neurological complications is summarized in Tables 3 and $\mathbf{4}$. 95\% confidence intervals (CI) for univariate analyses were calculated assuming normal distribution. Although the MELD score was greater in those with neurological complications, it was not statistically significant $(20$ vs. $24, p=0.06)$. Medical co-morbidities, such as hepatorenal syndrome (OR 2.9, 0.87-2.91), renal insufficiency (OR 2.23, 0.932.17 ), and intra-operative dialysis (OR 1.97, 0.80-2.25) were also risk factors associated with a greater rate of neurological complications. Furthermore, preoperative use of pressors (OR 2.72, 0.71-3.36), intubation (OR 2.8,0.78-3.15), and encephalopathy (OR 1.97, 0.86-2.09) were also factors associated with increased neurological complications based on the results of the univariate analysis.

On multivariate analysis, preoperative infection was the only independent predictor of neurological complications (OR 2.83, 1.49-5.53). There were a total of 50 patients who had preoperative infection, of which 32 (64\%) had neurological complications. The most common neurological complications in this group were encephalopathy (56.25\%) and tremor (21.88\%). Exclusion of intra-operative deaths did not change the study results.

\section{MORTALITY}

Overall, one-month mortality was $8.8 \%$. The MELD score was greater in the mortality group, but not statistically significant $(25$ vs. $22, p=0.181)$. Of the 20 deaths, six occurred intraoperatively (30\%). Characteristics of the 14 mortalities in the study population are listed in Table 5. Factors associated with mortality based on results of the univariate analysis are listed in Tables 6 and 7. 95\% CI for univariate analyses were calculated assuming normal distribution. Preoperative pressor use (OR 4.97, 0.78-5.19) and infection (OR 3.21, 0.78-3.15) as well as intraoperative cardiac arrest (OR 55.19, 1.00-32.63) and hypotension (OR 7.78, 0.94-6.34) were associated with greater mortality.

On multivariate analysis, independent predictors of one-month mortality included urgent re-transplant (OR 13.3, 2.9-55.53), preoperative intubation (OR 5.03, 1.54-13.14), and intraoperative arrhythmia (OR 5.75, 1.56-15.83).

\section{DISCUSSION}

The incidence of post-operative neurological complications after OLT in this study (44\%) was comparable to the incidence reported in the literature of approximately $10-47 \%(1,5)$. Previous studies 
Table 1 | Demographics of patients receiving liver transplant

\begin{tabular}{|c|c|c|c|c|}
\hline Category & Characteristics & $\begin{array}{l}\text { Entire study population, } \\
\text { number }(\%)(n=227)\end{array}$ & $\begin{array}{c}\text { No Neurological complications, } \\
\text { number }(\%)(n=129)\end{array}$ & $\begin{array}{c}\text { Neurological complications, } \\
\text { number }(\%)(n=98)\end{array}$ \\
\hline Gender & Male & $142(62.6)$ & $74(57.4)$ & $63(64.3)$ \\
\hline & Caucasian & $69(30.4)$ & $41(31.8)$ & $25(25.5)$ \\
\hline & Asian & $29(12.8)$ & $15(11.6)$ & $14(14.3)$ \\
\hline Donor type & Cadaveric (vs. partial living) & 181 (79.7) & 94 (72.9) & $81(82.7)$ \\
\hline \multirow[t]{3}{*}{ Transplant } & First transplant & $214(94.3)$ & $110(85.3)$ & 91 (92.9) \\
\hline & Urgent re-transplant & $8(3.5)$ & $4(3.1)$ & $4(4.1)$ \\
\hline & Non-urgent re-transplant & $5(2)$ & $9(7.0)$ & $3(3.1)$ \\
\hline & Alcohol & 36 (15.9) & $19(14.7)$ & $17(17.3)$ \\
\hline & Cryptogenic & $16(7)$ & & \\
\hline & Hepatitis B & $14(6.2)$ & $11(8.5)$ & $3(3.1)$ \\
\hline & Autoimmune & $10(4.4)$ & & \\
\hline & $\begin{array}{l}\text { Primary biliary cirrhosis, fulminant } \\
\text { failure, other }\end{array}$ & $6(2.6)$ & & \\
\hline & Metastasis & $3(1.3)$ & & \\
\hline & $\begin{array}{l}\text { Alpha } 1 \text { antitrypsin, amyloid, } \\
\text { polycystic liver, cholangiocarcinoma, } \\
\text { rejection, sclerosing cholangitis, } \\
\text { Wilson's }\end{array}$ & $2(0.9)$ & & \\
\hline
\end{tabular}

have found that most neurological complications usually occur in the first 3 months after OLT (1). Similar to prior studies, we focused our study on the first post-operative month $(4,5)$.

Our results revealed high rates of neurological complications and mortality after OLT in the post-MELD era. These high rates of morbidity and mortality may reflect the selection of candidates with more advanced liver disease. The study population had a mean MELD score of 22, consistent with the reported mean MELD of 24 in the United Network for Organ Sharing (UNOS) MELD 2003-2006 database (16).

With improved survival after OLT due to better perioperative care, operative techniques, and immune suppressive therapy, there has been increasing awareness of neurological complications (17). The main neurological complications include encephalopathy, seizure, immunosuppressant-related neurotoxicity, and peripheral nerve damage $(1,18)$, and the distribution of neurological complications in this study is similar to prior reports, with encephalopathy being the most common $(7,9,13,19,20)$. Established predictors of encephalopathy are alcoholism, metabolic dysregulation, MELD > 15, preoperative intubation, and non-elective liver transplant (21). Our findings demonstrated that neurological complications were not associated with one-month mortality. This lack of independent association suggests that encephalopathy, the most common neurological complication of this investigation, may present as a manifestation of other conditions such as infection or renal failure. Given these findings, the importance of separately considering encephalopathy when determining postoperative neurological events and mortality is worthy of additional study.

The primary aim of this investigation was to evaluate hypothesis-generating risk factors associated with post-operative neurological complications. We found that pre-operative infection was an independent predictor of such complications. Our study documented any infection in the week prior to surgery, including bacterial peritonitis and urinary tract infections. None of the patients who underwent OLT were septic at the time of surgery. Therefore, it appears that even mild or focal infections may be associated with an increased susceptibility to neurological events. This association is biologically plausible, as bacteria, viruses, and fungi can spread to the central nervous system just as they affect the abdomen, blood stream, respiratory tract, and other organ systems (22). Increases in incidence of encephalopathy and stroke were seen in patients with infection, possibly related to cerebral and vascular injury from the systemic inflammatory response. Systemic infection is particularly relevant as bacterial infections are common during the initial two months after transplantation and negatively affect both graft and patient survival (23). Transplant patients require high-dose immunosuppression, 
Table 2 | Neurologic complications during the first post-operative month after OLT

\begin{tabular}{|c|c|c|}
\hline Complication & $\begin{array}{c}\text { Cases }(n=98) \\
\text { number }(\%)\end{array}$ & $\begin{array}{c}\% \text { of total } \\
\text { population (227) }\end{array}$ \\
\hline Encephalopathy & $52(53.1)$ & 22.9 \\
\hline Tremor & $26(26.5)$ & 11.5 \\
\hline Hallucination & $11(11.2)$ & 4.8 \\
\hline Seizure & $8(8.2)$ & 3.5 \\
\hline Headache & $5(5.1)$ & 2.2 \\
\hline Intracerebral hemorrhage & $5(5.1)$ & 2.2 \\
\hline Ischemic stroke & $5(5.1)$ & 2.2 \\
\hline Myoclonus & $3(3.1)$ & 1.3 \\
\hline Anxiety & $2(2.0)$ & 0.9 \\
\hline Paresthesia & $2(2.0)$ & 0.9 \\
\hline Dysarthria & $2(2.0)$ & 0.9 \\
\hline Central pontine myelinolysis & $1(1.0)$ & 0.04 \\
\hline Neuropathy & $1(1.0)$ & 0.04 \\
\hline Intracranial infection & $1(1.0)$ & 0.04 \\
\hline Cerebral edema & $1(1.0)$ & 0.04 \\
\hline Subclinical status epilepticus & $1(1.0)$ & 0.04 \\
\hline Leg twitching & $1(1.0)$ & 0.04 \\
\hline Leg weakness & $1(1.0)$ & 0.04 \\
\hline Viral myositis & $1(1.0)$ & 0.04 \\
\hline Tinnitus & $1(1.0)$ & 0.04 \\
\hline $\begin{array}{l}\text { Posterior reversible } \\
\text { leukoencephalopathy }\end{array}$ & $1(1.0)$ & 0.04 \\
\hline
\end{tabular}

Table 3 | Univariate analysis of risk factors for neurologic complications following OLT.

\begin{tabular}{|c|c|c|}
\hline Variable & OR & $95 \% \mathrm{Cl}$ ( $p$-value) \\
\hline \multicolumn{3}{|l|}{ Medical comorbidity } \\
\hline Dialysis & 2.11 & $0.80-2.40(0.041)$ \\
\hline Hepatorenal syndrome & 2.9 & $0.87-2.91(0.01)$ \\
\hline Renal insufficiency & 2.23 & $0.93-2.17(0.006)$ \\
\hline \multicolumn{3}{|l|}{ Preoperative conditions } \\
\hline Encephalopathy & 1.97 & $0.86-2.09(0.023)$ \\
\hline Pressor use & 2.72 & $0.71-3.36(0.052)$ \\
\hline Intubation & 2.8 & $0.78-3.15(0.028)$ \\
\hline Infectiona & 2.83 & $0.98-2.52(0.002)$ \\
\hline \multicolumn{3}{|l|}{ Intra-operative events } \\
\hline Dialysis & 1.98 & $0.80-2.25(0.046)$ \\
\hline
\end{tabular}

Variables with $p<0.2$ are included.

a Significant on multivariate analysis.

exacerbating the potential for acquiring infection and developing neurological complications post-operatively $(11,23)$.

In our analyses of hypothesis-generating risk factors for onemonth mortality after OLT, re-transplantation within the first
Table 4 | Univariate analysis of laboratory risk factors for neurologic complications after OLT.

\begin{tabular}{lccl}
\hline Variable & $\begin{array}{c}\text { Mortality group } \\
\text { (level } \pm \text { SD) }\end{array}$ & $\begin{array}{c}\text { Survival group } \\
\text { (level } \pm \text { SD) }\end{array}$ & $\boldsymbol{p}$-Value \\
\hline MELD score & $23.51 \pm 11.9$ & $20.24 \pm 10.88$ & 0.056 \\
Hemoglobin (g/dL) & $10.72 \pm 1.91$ & $11.31 \pm 2.13$ & 0.03 \\
PTT (s) & $39.13 \pm 10.64$ & $36.23 \pm 8.49$ & 0.026 \\
INR (IU) & $1.73 \pm 0.84$ & $1.52 \pm 0.56$ & 0.06 \\
Number of intra- & $1.36 \pm 0.66$ & $1.15 \pm 0.75$ & 0.027 \\
operative pressors & & &
\end{tabular}

OLT: orthotopic liver transplantation; MELD: Model for end-stage liver disease; PTT: Partial thromboplastin time; INR: international normalized ratio. Laboratory values with $p<0.2$ are included.

Table 5 | Characteristics of the $\mathbf{1 4}$ mortalities in the study population

\begin{tabular}{|c|c|c|c|}
\hline Number & POD & Cause of death & $\begin{array}{l}\text { Neurological } \\
\text { complication }\end{array}$ \\
\hline 1 & 2 & Cardiogenic shock & None \\
\hline 2 & 2 & Sepsis & Encephalopathy \\
\hline 3 & 4 & Pulmonary embolism & Stroke, Myoclonus \\
\hline 4 & 5 & Cardiogenic shock & None \\
\hline 5 & 5 & Herniation & Cerebral Edema \\
\hline 6 & 6 & Cardiogenic shock & $\begin{array}{l}\text { Lower extremity } \\
\text { twitching }\end{array}$ \\
\hline 7 & 7 & $\begin{array}{l}\text { Cardiac arrest in later } \\
\text { surgery }\end{array}$ & None \\
\hline 8 & 12 & Sepsis & None \\
\hline 9 & 15 & Cardiogenic shock & None \\
\hline 10 & 19 & Herniation & $\begin{array}{l}\text { Intracerebral } \\
\text { Hemorrhage }\end{array}$ \\
\hline 11 & 21 & $\begin{array}{l}\text { Intracerebral } \\
\text { hemorrhage }\end{array}$ & $\begin{array}{l}\text { Intracerebral } \\
\text { Hemorrhage }\end{array}$ \\
\hline 12 & 26 & Sepsis & None \\
\hline 13 & 28 & Asystole after seizure & $\begin{array}{l}\text { Intracerebral Infection, } \\
\text { Seizure }\end{array}$ \\
\hline 14 & 29 & Sepsis & None \\
\hline
\end{tabular}

$P O D$, post-operative day.

month was independently associated with one-month mortality. Urgent liver re-transplant is necessary when complications such as primary non-function or vascular thrombosis cause the allograft to fail (24). Our mortality rate of $50 \%$ in the first month for acute re-transplant is comparable to other studies, which cite a two-month mortality rate of $51 \%$ in patients who acutely undergo re-transplantation (25). Urgent re-transplantation has been shown to have much lower survival rates compared to overall liver re-transplantations, and our results corroborate this finding (26). 
Table 6 | Univariate analysis of risk factors for one-month mortality following OLT.

\begin{tabular}{|c|c|c|}
\hline Variable & OR & $95 \%$ Cl (p-value) \\
\hline \multicolumn{3}{|l|}{ Transplant type } \\
\hline Urgent re-transplant* & 12.69 & $0.87-10.40(0.003)$ \\
\hline Non-urgent re-transplant & 3.48 & $0.55-5.38(0.094)$ \\
\hline \multicolumn{3}{|l|}{ Medical comorbidity } \\
\hline Pre-existing neurologic disease & 2.8 & $0.66-3.72(0.071)$ \\
\hline Recent surgery & 7.56 & $0.46-12.54(0.063)$ \\
\hline \multicolumn{3}{|l|}{ Preoperative conditions } \\
\hline Pressor use & 4.97 & $0.78-5.19(0.013)$ \\
\hline Intubation ${ }^{a}$ & 4.5 & $0.81-4.58(0.011)$ \\
\hline Infection & 3.21 & $0.78-3.51(0.021)$ \\
\hline \multicolumn{3}{|l|}{ Intraoperative events } \\
\hline Arrhythmia ${ }^{a}$ & 4.97 & $0.78-5.19(0.013)$ \\
\hline Cardiac arrest & 55.19 & $1.00-32.63(<0.001)$ \\
\hline Hypotension & 7.78 & $0.94-6.34(0.002)$ \\
\hline Race & N/A & N/A (0.169) \\
\hline
\end{tabular}

Variables with $p<0.2$ are included.

a Significant on multivariate analysis.

Table 7 | Univariate analysis of laboratory risk factors of one-month mortality following OLT.

\begin{tabular}{lccc}
\hline Variable & $\begin{array}{c}\text { Mortality group } \\
\text { (level } \pm \text { SD) }\end{array}$ & $\begin{array}{c}\text { Survival group } \\
\text { (level } \pm \text { SD) }\end{array}$ & $\boldsymbol{p}$-Value \\
\hline MELD score & $24.75 \pm 10.59$ & $21.47 \pm 11.42$ & 0.181 \\
Hemoglobin (g/dL) & $9.94 \pm 1.45$ & $11.1 \pm 2.09$ & 0.024 \\
PTT (s) & $40.34 \pm 11.21$ & $37.41 \pm 9.41$ & 0.185 \\
INR (IU) & $1.99 \pm 1.3$ & $1.6 \pm 0.7$ & 0.151 \\
Albumin (g/dL) & $2.65 \pm 0.7$ & $3.11 \pm 2.07$ & 0.068 \\
Number of intra- & $1.95 \pm 1.1$ & $1.19 \pm 0.68$ & 0.001 \\
operative pressors & & &
\end{tabular}

OLT: orthotopic liver transplantation; MELD: Model for end-stage liver disease; PTT: Partial thromboplastin time; INR: international normalized ratio. Laboratory values with $p<0.2$ are included.

Pre-operative intubation also was an independent predictor of one-month mortality, a finding that has not been reported in prior studies of complications after OLT. One study has demonstrated that among patients who underwent emergency or elective living-donor liver transplantation (LDLT), those who underwent emergency LDLT had higher rates of pre-operative intubation, suggesting greater pre-transplant acuity and possibly poorer posttransplant outcome (27). Further, intraoperative arrhythmias were also independently associated with one-month mortality, corroborating studies that have suggested patients with atrial fibrillation may be at increased risk of mortality after liver transplantation $(28,29)$. Despite these few reports, risk factors associated with mortality after OLT have not been well characterized in the literature. Our results contribute to an improved understanding of the risk factors for post-transplant mortality in a vulnerable patient population.

While prior study populations were predominantly Caucasian, our study population was predominantly Hispanic. Studies have demonstrated poorer outcomes in minority populations, particularly African Americans (30). Some research has suggested that liver transplantation among Hispanics has excellent outcomes compared to non-Hispanics (31), while other studies have highlighted suboptimal outcomes among minority populations, including greater mortality rates (31-34). Our results demonstrated that African American and Hispanic patients had greater mortality than Caucasian patients. Though no factors were identified to explain these differences, possibilities include immunologic and genetic differences between recipients and donors.

The main limitation of this investigation is its retrospective design. It is possible that not all neurological findings were documented in the patient charts, resulting in an underestimation of some results. Our one-month follow-up may have missed neurological complications that occurred later in the post-operative course. Nevertheless, the findings contribute to a growing body of literature that examines neurological complications after OLT $(12,19,28)$.

In summary, neurological complications after OLT are common in the post-MELD era, with encephalopathy being the most common complication. Infection was independently associated with the development of post-operative neurological complications, suggesting that these complications may be reduced by treating infection during the preoperative period. In addition, urgent re-transplant, preoperative intubation, and intraoperative arrhythmias were independent predictors of one-month mortality after OLT. Identifying hypothesis-generating risk factors for both the development of neurological complications and one-month mortality supports a better understanding of the population most at risk for adverse outcomes after transplantation.

Future studies might investigate the role of infection in neurological complications to better determine the pathophysiology involved in conditions such as encephalopathy and ischemic stroke among OLT patients. Similarly, factors this investigation revealed to be associated with one-month mortality after OLT, such as intraoperative arrhythmias, have been less well-characterized in the literature and warrant further investigation to clarify their impact on outcomes. An improved understanding of these hypothesisgenerating risk factors for neurological complications and onemonth mortality after liver transplantation ultimately may reduce adverse outcomes and improve graft and patient survival.

\section{ACKNOWLEDGMENTS}

The authors thank Dr. Linda Chan Ph.D. for help with statistics. This work was supported in part by Health Resources and Services Administration contract 234-2005-37011C. The content is the responsibility of the authors alone and does not necessarily reflect the views or policies of the Department of Health and Human Services, nor does mention of trade names, commercial products, or organizations imply endorsement by the U.S. Government. This work was supported by funding from the Roxanna Todd Hodges Foundation and Joachim Splichal. 


\section{REFERENCES}

1. Amodio P, Biancardi A, Montagnese S, Angeli P, Iannizzi P, Cillo U, et al. Neurological complications after orthotopic liver transplantation. Dig Liver Dis (2007) 39(8):740-7. doi:10.1016/j.dld.2007.05.004

2. Mazariegos GV, Molmenti EP, Kramer DJ. Early complications after orthotopic liver transplantation. Surg Clin North Am (1999) 79(1):109-29. doi:10.1016/ S0039-6109(05)70009-8

3. Saner F, Gu Y, Minouchehr S, Ilker K, Fruhauf NR, Paul A, et al. Neurological complications after cadaveric and living donor liver transplantation. J Neurol (2006) 253(5):612-7. doi:10.1007/s00415-006-0069-3

4. Borhani Haghighi A, Malekhoseini SA, Bahramali E, Firouzabadi N, Salahi $\mathrm{H}$, Bahador A, et al. Neurological complications of first 100 orthotopic liver transplantation patients in southern Iran. Transplant Proc (2005) 37(7):3197-9. doi:10.1016/j.transproceed.2005.08.025

5. Boin IF, Falcao AE, Luzo AC, Cardoso AR, Caruy CA, Leonardi LS. Analysis of neurologic complications within the first 30 days after orthotopic liver transplantation. Transplant Proc (2001) 33(7-8):3695-6. doi:10.1016/S00411345(01)02507-6

6. Dhar R, Young GB, Marotta P. Perioperative neurological complications after liver transplantation are best predicted by pre-transplant hepatic encephalopathy. Neurocrit Care (2008) 8(2):253-8. doi:10.1007/s12028-007-9020-4

7. Ghaus N, Bohlega S, Rezeig M. Neurological complications in liver transplantation. J Neurol (2001) 248(12):1042-8. doi:10.1007/s004150170023

8. Dhar R, Human T. Central nervous system complications after transplantation. Neurol Clin (2011) 29(4):943-72. doi:10.1016/j.ncl.2011.07.002

9. Bronster DJ, Emre S, Boccagni P, Sheiner PA, Schwartz ME, Miller CM. Central nervous system complications in liver transplant recipients - incidence, timing, and long-term follow-up. Clin Transplant (2000) 14(1):1-7. doi:10.1034/j.1399-0012.2000.140101.x

10. Bechstein WO. Neurotoxicity of calcineurin inhibitors: impact and clinical management. Transpl Int (2000) 13(5):313-26. doi:10.1111/j.1432-2277.2000. tb01004.x

11. Tolou-Ghamari Z. Nephro and neurotoxicity of calcineurin inhibitors and mechanisms of rejections: a review on tacrolimus and cyclosporin in organ transplantation. J Nephropathol (2012) 1(1):23-30. doi:10.5812/jnp.6

12. Kim BS, Lee SG, Hwang S, Park KM, Kim KH, Ahn CS, et al. Neurologic complications in adult living donor liver transplant recipients. Clin Transplant (2007) 21(4):544-7. doi:10.1111/j.1399-0012.2007.00687.x

13. Lewis MB, Howdle PD. Neurologic complications of liver transplantation in adults. Neurology (2003) 61(9):1174-8. doi:10.1212/01.WNL.0000089487. 42870.C6

14. Brown RS Jr, Kumar KS, Russo MW, Kinkhabwala M, Rudow DL, Harren P, et al. Model for end-stage liver disease and Child-Turcotte-Pugh score as predictors of pretransplantation disease severity, posttransplantation outcome, and resource utilization in United Network for Organ Sharing status 2A patients. Liver Transpl (2002) 8(3):278-84. doi:10.1053/jlts.2002.31340

15. Campagna F, Biancardi A, Cillo U, Gatta A, Amodio P. Neurocognitiveneurological complications of liver transplantation: a review. Metab Brain Dis (2010) 25(1):115-24. doi:10.1007/s11011-010-9183-0

16. 2006 Annual Report of the U.S. Organ Procurement and Transplantation Network and the Scientific Registry of Transplant Recipients: Transplant Data 1996-2005. Health Resources and Services Administration, Healthcare Systems Bureau, Division of Transplantation, Rockville, MD (2006). Available from: http://www. srtr.org/annual_reports/archives/2006/2006_Annual_Report/default.htm

17. Saner FH, Sotiropoulos GC, Radtke A, Fouzas I, Molmenti EP, Nadalin S, et al. Intensive care unit management of liver transplant patients: a formidable challenge for the intensivist. Transplant Proc (2008) 40(9):3206-8. doi:10.1016/j.transproceed.2008.08.069

18. Stracciari A, Guarino M. Neuropsychiatric complications of liver transplantation. Metab Brain Dis (2001) 16(1-2):3-11. doi:10.1023/A:1011698526025

19. Saner FH, Gensicke J, Olde Damink SW, Pavlakovic G, Treckmann J, Dammann $\mathrm{M}$, et al. Neurologic complications in adult living donor liver transplant patients: an underestimated factor? J Neurol (2010) 257(2):253-8. doi:10.1007/s00415009-5303-3

20. Saner FH, Sotiropoulos GC, Gu Y, Paul A, Radtke A, Gensicke J, et al. Severe neurological events following liver transplantation. Arch Med Res (2007) 38(1):75-9. doi:10.1016/j.arcmed.2006.07.005
21. Kanwal F, Chen D, Ting L, Gornbein J, Saab S, Durazo F, et al. A model to predict the development of mental status changes of unclear cause after liver transplantation. Liver Transpl (2003) 9(12):1312-9. doi:10.1016/j.lts.2003.09.023

22. Feltracco P, Barbieri S, Furnari M, Milevoj M, Rizzi S, Galligioni H, et al. Central nervous system infectious complications early after liver transplantation. Transplant Proc (2010) 42(4):1216-22. doi:10.1016/j.transproceed.2010.03.108

23. Kim SI. Bacterial infection after liver transplantation. World J Gastroenterol (2014) 20(20):6211-20. doi:10.3748/wjg.v20.i20.6211

24. Bellido CB, Martinez JM, Gomez LM, Artacho GS, Diez-Canedo JS, Pulido LB, et al. Indications for and survival after liver retransplantation. Transplant Proc (2010) 42(2):637-40. doi:10.1016/j.transproceed.2010.02.017

25. Ferraz-Neto BH, Zurstrassen MP, Hidalgo R, Rezende MB, Meira-Filho SP, Pandullo FL, et al. Results of urgent liver retransplantation in the state of Sao Paulo, Brazil. Transplant Proc (2006) 38(6):1911-2. doi:10.1016/j.transproceed.2006. 06.073

26. Gustafsson BI, Backman L, Friman S, Herlenius G, Lindner P, Mjornstedt L, et al. Retransplantation of the liver. Transplant Proc (2006) 38(5):1438-9. doi:10.1016/j.transproceed.2006.02.120

27. Takeda K, Tanaka K, Kumamoto T, Nojiri K, Mori R, Taniguchi K, et al. Emergency versus elective living-donor liver transplantation: a comparison of a single center analysis. Surg Today (2012) 42(5):453-9. doi:10.1007/s00595-0110040-5

28. Vannucci A, Rathor R, Vachharajani N, Chapman W, Kangrga I. Atrial fibrillation in patients undergoing liver transplantation-a single-center experience. Transplant Proc (2014) 46(5):1432-7. doi:10.1016/j.transproceed.2014. 02.020

29. Bargehr J, Trejo-Gutierrez JF, Rosser BG, Patel T, Yataco ML, Pungpapong S, et al. Liver transplantation in patients with atrial fibrillation. Transplant Proc (2013) 45(6):2302-6. doi:10.1016/j.transproceed.2013.02.130

30. Callender CO, Cherikh WS, Miles PV, Hermesch A, Maddox G, Nash J, et al. Blacks as donors for transplantation: suboptimal outcomes overcome by transplantation into other minorities. Transplant Proc (2008) 40(4):995-1000. doi:10.1016/j.transproceed.2008.03.063

31. Mejia A, Halff GA, Esterl R, Cigarroa F, Speeg KV, Villarreal R, et al. Outcome of liver transplantation in Hispanics versus non-Hispanics: is there a difference? Transplant Proc (2002) 34(4):1236-8. doi:10.1016/S0041-1345(02)02799-9

32. Nair S, Eustace J, Thuluvath PJ. Effect of race on outcome of orthotopic liver transplantation: a cohort study. Lancet (2002) 359(9303):287-93. doi:10.1016/ S0140-6736(02)07494-9

33. Mathur AK, Schaubel DE, Gong Q, Guidinger MK, Merion RM. Racial and ethnic disparities in access to liver transplantation. Liver Transpl (2010) 16(9):1033-40. doi:10.1002/lt.22108

34. Mathur AK, Schaubel DE, Zhang H, Guidinger MK, Merion RM. Disparities in liver transplantation: the association between donor quality and recipient race/ethnicity and sex. Transplantation (2014) 97(8):862-9. doi:10.1097/01.tp. 0000438634.44461 .67

Conflict of Interest Statement: The authors declare that the research was conducted in the absence of any commercial or financial relationships that could be construed as a potential conflict of interest.

Received: 07 October 2014; accepted: 03 December 2014; published online: 17 December 2014.

Citation: Fu KA, DiNorcia J, Sher L, Velani SA, Akhtar S, Kalayjian LA and Sanossian $N$ (2014) Predictive factors of neurological complications and one-month mortality after liver transplantation. Front. Neurol. 5:275. doi: 10.3389/fneur.2014.00275

This article was submitted to Neurocritical and Neurohospitalist Care, a section of the journal Frontiers in Neurology.

Copyright (C) 2014 Fu, DiNorcia, Sher, Velani, Akhtar, Kalayjian and Sanossian. This is an open-access article distributed under the terms of the Creative Commons Attribution License (CC BY). The use, distribution or reproduction in other forums is permitted, provided the original author(s) or licensor are credited and that the original publication in this journal is cited, in accordance with accepted academic practice. No use, distribution or reproduction is permitted which does not comply with these terms. 